greater than the normal by more than I-Iooth part. Finally, the normal value was gradually reached again at $7 \mathrm{~h} .30 \mathrm{~m}$.

In the second magnetic storm, the range of the declination movements was $\mathrm{I}^{\circ} 3 \mathrm{O}^{\prime}$, of the horizontal force about $\mathrm{I}$-50th part of the whole, and of the vertical force about $\mathrm{I} \cdot \mathrm{I}$ 20th part.

Thus the vertical force disturbance on April I9-20 was comparatively small; that of the vertical force on April 16-17 is characteristic of the greatest storms, and since the great disturbances of $1872, \mathrm{February} 4$, and those of October 4 of the same year, no magnetic storm has been recorded equal to thi Earth-currents were shown throughout both storms.

Royal Observatory, Greenwich, May 8

$$
\text { W. H. M. Christie }
$$

\section{Hypothetical High Tides}

I REGRET that I am not able to accept the criticisms of Mr. C. Callaway on my notice of Prof. Ball's lecture. I have studied the effect of tidal and wind waves on many coasts through many years, and my observations do not warrant the statements he makes. Every schoolboy knows the distinction between waves of undulation and translation, and it is in no sense true that I have confused them. With waves of undulation such as occur in mid ocean we have nothing to do in this discussion, but it cannot be unknown to Mr. Callaway that all such waves when reaching a shore, become waves of translation, and more or less powerful denuding agents. If he will have the kindness to refer to my "Report on the Geology of Ohio," vol. i. pp. 52, \&c., he will find that I have done ample justice to the efficiency of wind waves as agents of geological change. The great tidal current rushing around the earth, with which he credits me, exists only in his own imagination. I have suggested nothing of the kind, but the rapid ebb and flow over the shores of continent of tidal waves several hundred feet in height must necessarily act with great violence upon such shores, and I insist that such tidal waves as pictured by Prof. Ball would have left a very different record from that we find in our Palæozoic rocks. Some of our American Silurian strata were deposited on shores that faced toward the east, where they had an unbroken stretch of several thousands of miles of ocean over which the tidal wave would come to them without obstruction, and there the maximum effect of such tides as Prof. Ball describes would be produced, but no traces of them are found.

I am aware that the reef-building corals of the Devonian were zoologically distinct from any now living, and for that reason conditioned my inference from them; but we have satisfactory evidence that the Devonian coral reefs of Ohio and Kentucky were formed along a shore and in a warm sea, like the reefbuilding corals of the present day, and there are many reasons for believing that their mode of life was the same.

The point made by Mr. Searles Wood in regard to the coal, though objected to by Mr. Callaway, is well taken, for we know that the great coal marshes of America were located just at the sea level, and from time to time were inundated by the sea and covered with sheets of marine limestone. It requires no argument to show that the growth of the Carboniferous forests and the formation of beds of peat-now coal-could not have taken place with tides rising one-half or even one-fourth of the height of those described by Prof. Ball.

On carefully reviewing the facts which suggested my objection to Prof. Ball's theory, I am compelled to reiterate the statement before made, that on the east coast of North America the geological record bears positive and conclusive testimony against the high tide theory, and that at least since the Archæan ages no tides have swept this coast like those required by Prof. Ball's theory, even as modified by Mr. Darwin.

New York, April ro

\section{J. S. NEWBERRY}

\section{Aurora Borealis}

A POLAR aurora of remarkable activity and brilliancy was observable here at II.I5 last night. The centre of energy at the time of origin was under Cassiopiea, a highly luminous streamer shooting upwards from the horizon, and covering, but not hiding the stars in that constellation. Brilliant white flick ering streamers and rays, arising from the horizon, quickly spread towards the north-west, and an irregular shaped mass of crimson light, of an altitude of $45^{\circ}$, and many degrees in breadth, appeared, and suffused the northern hemisphere from Cassiopiea to Gemini. Between the horizon and the mass of crimson-coloured vapour the sky was of a light green hue, and upwards, through this area of greenish light, the rays and streamers shot.

During the period of greatest energy, a beam of vivid light arose towards the north-west, was projected over Gemini, and quite extinguished the light of the two large stars in that constellation. About midnight the meteor faded. Soon afterwards the sky became overcast. Throughout the day the wind had been blowing briskly and coldly from a point in the north-east. Barometer, highest during the day in the shade, 60; aneroid, $30 \%$. In the afternoon, curious slender-rayed cirri from the north-west, generally indicative to my mind of auroral disturbanie, cros:ed the northern sky towards the zenith. To-day, detached clouds and blue sky, and the wind is blowing stiffly and icily from the same point. Barometer and aneroid. same as yesterday, the latter inclined to full.

An auroral display of the like splendour and activity is very rare, if not wholly unknown in this locality at this time of the year.

Worcester, May 15

$\mathrm{X}$.

AT IO'55 p.m. last night, I observed a very beautiful aurora borealis, consisting mainly of three beams, nearly vertical, and then parallel to the direction of the stars $\alpha$ and $\delta$ of the Great Bear. They moved slowly towards the east, and about II $^{\circ} 5$ faded away. About II o'clock they were very bril iant, and the central beam, then quite close to the Polar star presented a slightly purple or violet colour, as represented in the sketch inclosed. Ntar the earth, and at about $15^{\circ}$ to $20^{\circ}$ elevation, there was a mass or cloud of suffused light, from which the beams seemed to rise. It seems that an aurora was also seen about a fortnight ago from Dublin. The wind has been easterly, and to-day is somewhat colder than yesterday.

Royal College of Science, Dublin, May I4

$$
\text { J. P. O'REILly }
$$

\section{Spectrum of Wells' Comet}

THE continuous spectrum of this comet, especially of the nucleus, is remarkably bright. $\mathrm{I}$ observed it on April 18 and May 6 and 15. There were at least three bright bands, and perhaps more. I believe the usual three were visible, but they were so indistinct that I did not observe their positions. The middle one was much the brightest, and the only one plainly visible. I never saw a comet in which the bright bands were s: faint, relative to the continuous spectrum. May 16

\section{T. W. Backhouse}

\section{The Recent Violent Storm}

MAY I ask your permission to insert from me a curious circumstance, which came under my notice, soon after the tremendous storm which took place on Saturday, April 29 last. On the glass of some of the windows of the house in which I reside I perce ved a very singular appearance upon them, somewhat resembling a deposit from milk. On looking at it through a microscope I discovered a number of very beautiful crystals, which, without doubt, were caused by the spray from the sea, as on applying it to the tongue, there was a strong taste of salt. The distance the spray must have been carried on this occasion could not have been less than sixty miles, taking into considera. tion the course of the wind, which was south-west.

Waddon, Croydon, Surrey, May I 5

$$
\text { Nathaniel Waterall }
$$

\section{The Cuckoo}

Is it a normal habit, or only an erratic freak of that quaint bird, the cuckoo, to sing at night. On the night of Monday, the 8th inst., I first heard, at Io p.m., three or four calls, but took little notice of it, thinking the bird had been startled from his dreams, but in a short time he recommenced, and went on continuously with short intervals of silence, until I2 or I, precisely as by day.

It was a dark night with only dim starlight. I should like to know whether others bave remarked this nocturnal loquacity in the cuckoo. This particular bird has usually commenced his song or call at about $4 \mathrm{a}, \mathrm{m}$.

May I I 